\title{
Self-Assembly of Short Chain Poly- $N$-isopropylacrylamid Induced by Superchaotropic Keggin Polyoxometalates: From Globules to Sheets
}

Thomas Buchecker, ${ }^{\dagger \dagger}$ Philipp Schmid, ${ }^{\dagger,}$ Isabelle Grillo, ${ }^{\S}$ Sylvain Prévost, ${ }^{\prime \prime}$ Markus Drechsler, ${ }^{\perp}$ Olivier Diat, ${ }^{\ddagger}$ Arno Pfitzner, ${ }^{+0}$ and Pierre Bauduin*, ${ }^{*}$

${ }^{\dagger}$ Institute of Inorganic Chemistry, University of Regensburg, 93040 Regensburg, Germany

${ }^{\ddagger}$ ICSM, CEA, CNRS, ENSCM, Univ Montpellier, 34199 Marcoule, France

${ }^{\S}$ Institut Laue-Langevin, 6 rue Jules Horowitz, Grenoble Cedex 9 38042, France

"ESRF - The European Synchrotron Radiation Facility, 3800 Grenoble, France

${ }^{\perp}$ Laboratory of Soft Matter Electron Microscopy, University of Bayreuth, 95440 Bayreuth, Germany

Supporting Information

ABSTRACT: We show here for the first time that short chain poly( $N$-isopropylacrylamide) (PNIPAM), one of the most famous thermoresponsive polymers, self-assembles in water to form (i) discrete nanometer-globules and (ii) micrometric sheets with nm-thickness upon addition of the well-known Keggin-type polyoxometalate (POM) $\mathrm{H}_{3} \mathrm{PW}_{12} \mathrm{O}_{40}(\mathrm{PW})$. The type of self-assembly is controlled by $\mathrm{PW}$ concentration: at low PW concentrations, PW adsorbs on PNIPAM chains to form globules consisting of homogeneously distributed PWs in PNIPAM droplets of several $\mathrm{nm}$ in size. Upon further

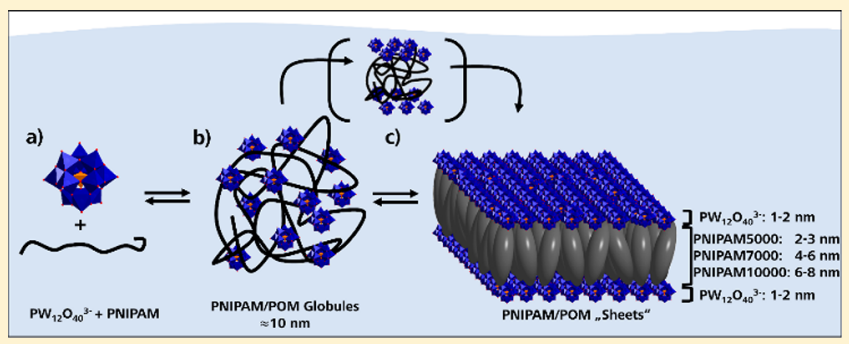
addition of PW, a phase transition from globules to micrometric sheets is observed for PNIPAMs above a polymer critical chain length, between 18 and 44 repeating units. The thickness of the sheets is controlled by the PNIPAM chain length, here from 44 to 88 repeating units. The PNIPAM sheets are electrostatically stabilized PWs accumulated on each side of the sheets. The shortest PNIPAM chain with 18 repeating units produces PNIPAM/PW globules with 5-20 nm size but no sheets. The PW/ PNIPAM self-assembly arises from a solvent mediated mechanism associated with the partial dehydration of PW and of the PNIPAM, which is related to the general propensity of POMs to adsorb on neutral hydrated surfaces. This effect, known as superchaotropy, is further highlighted by the significant increase in the lower critical solubilization temperature (LCST) of PNIPAM observed upon the addition of $\mathrm{PW}$ in the $\mathrm{mM}$ range. The influence of the POM nature on the self-assembly of PNIPAM was also investigated by using $\mathrm{H}_{4} \mathrm{SiW}_{12} \mathrm{O}_{40}(\mathrm{SiW})$ and $\mathrm{H}_{3} \mathrm{PMo}_{12} \mathrm{O}_{40}$ (PMo), i.e. changing the POM's charge density or polarizability in order to get deeper understanding on the role of electrostatics and polarizability in the PNIPAM selfassembly process. We show here that the superchaotropic behavior of POMs with PNIPAM polymers enables the formation and the shape control of supramolecular organic-inorganic hybrids.

\section{INTRODUCTION}

Poly(N-isopropylacrylamide) (PNIPAM), one of the most studied thermoresponsive polymers, undergoes a liquid-liquid phase separation in aqueous solutions above its lower critical solution temperature (LCST) around $33{ }^{\circ} \mathrm{C} .{ }^{1,2}$ During this process, single PNIPAM polymers undergo a conformational change form a hydrated "swollen" extended conformation to a dehydrated "shrunk" globular conformation., ${ }^{2,3}$ As the LCST of PNIPAM appears close to body temperature PNIPAM polymers find several applications in (i) biotechnology where, e.g. the LCST is exploited in the bioseparation of proteins conjugated with PNIPAM, or in (ii) (surface-) functionalization of materials to grant them thermoresponsiveness. ${ }^{4}$ PNIPAM is also (iii) a model polymer for the cold denaturation of proteins in aqueous solution, as PNIPAM has secondary amide side groups reminiscent of the polyamide backbone of proteins. ${ }^{4,5}$ The use of PNIPAM in physiological media requires a deep understanding of the conformational and solution behavior of PNIPAM in the presence of salt., ${ }^{4,-14}$ The most comprehensive studies on the effect of salt, chain length and end group polarity on the LCST and solubility of PNIPAM in water have been carried out by the group of P. S. Cremer. ${ }^{11,12,15,16}$ Although $\mathrm{Du}$ et al. stressed by virtue of molecular dynamics (MD)-simulations that PNIPAM interacts predominantly with cations, ${ }^{6}$ Pérez-Fuentes et al. showed by combining MD-simulations and experiments that for anions/ cations with identical size, shape and valence, the affinity of anions and cations for interfaces is intrinsically different, with anions providing a substantially stronger impact on PNIPAM than cations. ${ }^{7}$ The PNIPAM chain polymer dimensions have been lately extensively and carefully investigated by others,

Received: November 13, 2018

Published: April 5, 2019 
depending on chain hydration at different temperatures and for different compositions. ${ }^{17-20}$ Cremer et al. focused on the interaction of PNIPAM with sodium salts of different anions. They proposed that anions can interact with the PNIPAM polymer via three pathways: (i) anions can polarize water molecules that are involved in hydrogen bonding with the amide bond, (ii) anions can interfere with the hydrophobic hydration of the macromolecule by increasing the surface tension of the cavity surrounding the hydrophobic aliphatic backbone and the isopropyl groups and (iii) anions may bind directly to the polyamide group. They claimed that (i) and (ii) lead to a decrease of the water solubility of PNIPAM (called salting-out, i.e. lowering the LCST of PNIPAM) whereas (iii) leads to an increase of the water solubility of PNIPAM (called salting in, i.e. increasing the LCST of PNIPAM). Cremer et al. concluded that the ability of an anion to lower the LCST generally follows the well-known Hofmeister series of anions ${ }^{21}$ implying that kosmotropic anions (small anions with high charge density) are strongly salting out whereas chaotropic anions (large anions with low charge density, typically $\mathrm{SCN}^{-}$ or $\mathrm{I}^{-}$) are salting-in by adsorbing on PNIPAM chains. ${ }^{15}$

Recently, we have shown that POMs, anionic nanosized molecular metal oxide clusters, are by far more chaotropic than classical chaotropic anions (e.g., $\mathrm{I}^{-}$or $\mathrm{SCN}^{-}$), due to their large size, low charge density and delocalized charges. Different Keggin, see Figure 1a, and Wells-Dawson type POMs (as

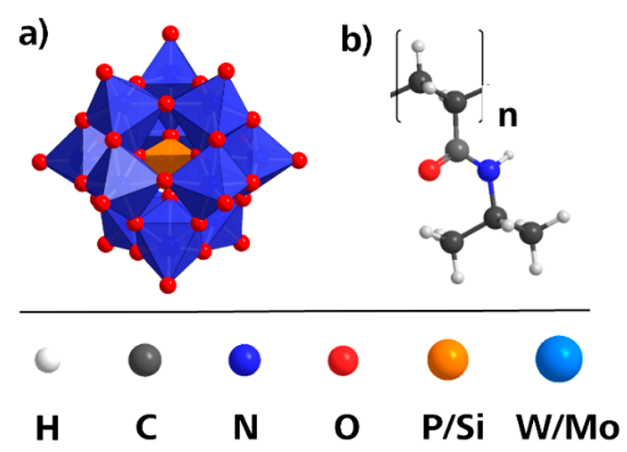

Figure 1. Structure of (a) $\alpha$-Keggin-type POMs: $\alpha$ - $\mathrm{H}_{3} \mathrm{PW}_{12} \mathrm{O}_{40}(\mathrm{PW}$ ), $\alpha-\mathrm{H}_{3} \mathrm{PMo}_{12} \mathrm{O}_{40}(\mathrm{PMo})$ and $\alpha-\mathrm{H}_{4} \mathrm{SiW}_{12} \mathrm{O}_{40}(\mathrm{SiW})$, the $\mathrm{H}^{+}$, counterions of the POMs, are omitted here, and (b) the nonionic thermoresponsive polymer: poly- $N$-isopropylacrylamide (PNIPAM). The PNIPAMs investigated here have averaged polymerization degrees, $n$, of $18,44,62$ and 88 respectively, for PNIPAM2000, 5000, 7000 and 10000 .

acidic and potassium salts) were classified within the Hofmeister series as superchaotropes due to their extremely strong increase in the clouding temperature of nonionic polyethoxylated surfactants. The increase in the clouding temperature was typically ranging between 10 and $40{ }^{\circ} \mathrm{C}$ for POMs compared to around $2-3{ }^{\circ} \mathrm{C}$ for $\mathrm{SCN}^{-}$for salt concentrations in the $\mathrm{mM}$ range. ${ }^{2-24}$ The superchaotropic behavior of POMs is related to their strong propensity to adsorb on hydrated neutral surfaces, e.g. on nonionic surfactant micelles surface made of polyethoxylated or sugar-based surfactants, ${ }^{22,24}$ at the water/air interface covered by the latter nonionic surfactants, ${ }^{22}$ on polyethylene glycol ( $\mathrm{EO}_{n}$ or PEG) oligomers $^{23}$ or cyclodextrins. ${ }^{22-27}$ The affinity of nanoions toward hydrated surfaces or hydrated oligomers, i.e. the strength of their superchaotropic behavior, appears to be primarily related to their charge density ${ }^{23}$ which is the major contribution to the strength of ion hydration. ${ }^{28}$ It was proposed that the strong adsorption of superchaotropes on hydrated surfaces is a process associated with the release of water molecules in the bulk, arising from the partial dehydratation of the surface and of the superchaotropes upon surface adsorption. ${ }^{22,29,30} \mathrm{Nau}$ et al. proposed that the association process between boranes, another type of superchaotrope anions $\left(\mathrm{B}_{12} \mathrm{X}_{12}{ }^{2-}\right.$ with $\mathrm{X}=\mathrm{H}, \mathrm{Cl}, \mathrm{Br}$ or $\left.\mathrm{I}\right)$, with cyclodextrin is related to the recovery of water structure upon association. As for Hofmeister's, or specific ion-effects, the superchaotropic effect emerges from nonspecific interactions and results from ion-water/water surface interactions, which is sometimes referred to as a "solvent-mediated" effect. ${ }^{15,31}$ It is noteworthy that the superchaotropic behavior is not restricted only to POMs but can apparently be generalized to nanometric anionic species with a low charge density, such as anionic boron clusters. ${ }^{29,32}$

Self-assembly and nanostructures based on POMs are generally produced by two approaches: the covalent grafting $^{33-36}$ and the electrostatic coupling, ${ }^{37-41}$ which sometimes refers to the terms "surfactant encapsulated clusters" (SEC) or "POMs" (SEP). The superchaotropic effect differs then from these two latter approaches as it is based on noncovalent and nonpurely electrostatic interactions. The superchaotropic effect of POMs has recently opened some opportunities to finely control the multiscale structures of nanohybrids, e.g. by investigating their interactions with cyclodextrins. $^{26,27}$

Here, we investigate the superchaotropic effect of Keggin type polyoxometalates, $\alpha-\mathrm{H}_{3} \mathrm{PW}_{12} \mathrm{O}_{40}(\mathrm{PW}), \alpha-\mathrm{H}_{3} \mathrm{PMo}_{12} \mathrm{O}_{40}$ (PMo) and $\alpha-\mathrm{H}_{4} \mathrm{SiW}_{12} \mathrm{O}_{40}(\mathrm{SiW})$, on short chain PNIPAM polymers (PNIPAM2000, 5000, 7000 and 10000 with average $18,44,62$ and 88 repeating units, respectively), see Figure 1. To the best of our knowledge the (nonspecific) interactions between POMs and PNIPAM as well as the self-assembly of PNIPAM in well-defined nanostructures were so far not reported in the literature. The covalent grafting of PNIPAM to POMs has been explored recently to induce self-assembly, thermo- and salt-sensitivity to POMs. ${ }^{35}$ We investigate here (i) the noncovalent and non- purely electrostatic interactions of anionic POMs with neutral PNIPAM, i.e. the superchaotropic effect, by investigating their assembly process in water and (ii) the thermal response of PNIPAM, i.e. the evolution of the LCST upon addition of POMs and by differential scanning calorimetry (DSC) measurements. The structures of PNI$\mathrm{PAM} / \mathrm{POM}$ assemblies at the mesoscale were determined by synchrotron small-angle-X-ray-scattering (SAXS) and smallangle neutron scattering (SANS) in combination with cryotransmission electron microscopy (cryo-TEM).

\section{RESULTS AND DISCUSSION}

PW/PNIPAM10000 System. The addition of PW above 5 $\mathrm{mM}$ to a $1 \mathrm{mM}$ PNIPAM10000 solution leads to the appearance of a blueish shade, see the picture inserted in Figure 3 (inset at $25^{\circ} \mathrm{C}$ ). This blue color arises from the scattering of the blue radiation of light (Tyndall scattering) and suggests the formation of large structures $(>10-100 \mathrm{~nm})$ in solution. It is important to note that the blue color is a characteristic of reduced POMs, known as heteropoly blue species, where the mixed valence states exhibit a bright blue color. UV-vis spectroscopy was used to give clear evidence that the blue color arises from Tyndall effect and not from reduced POM species, see the discussion in SI and Figure S1. 


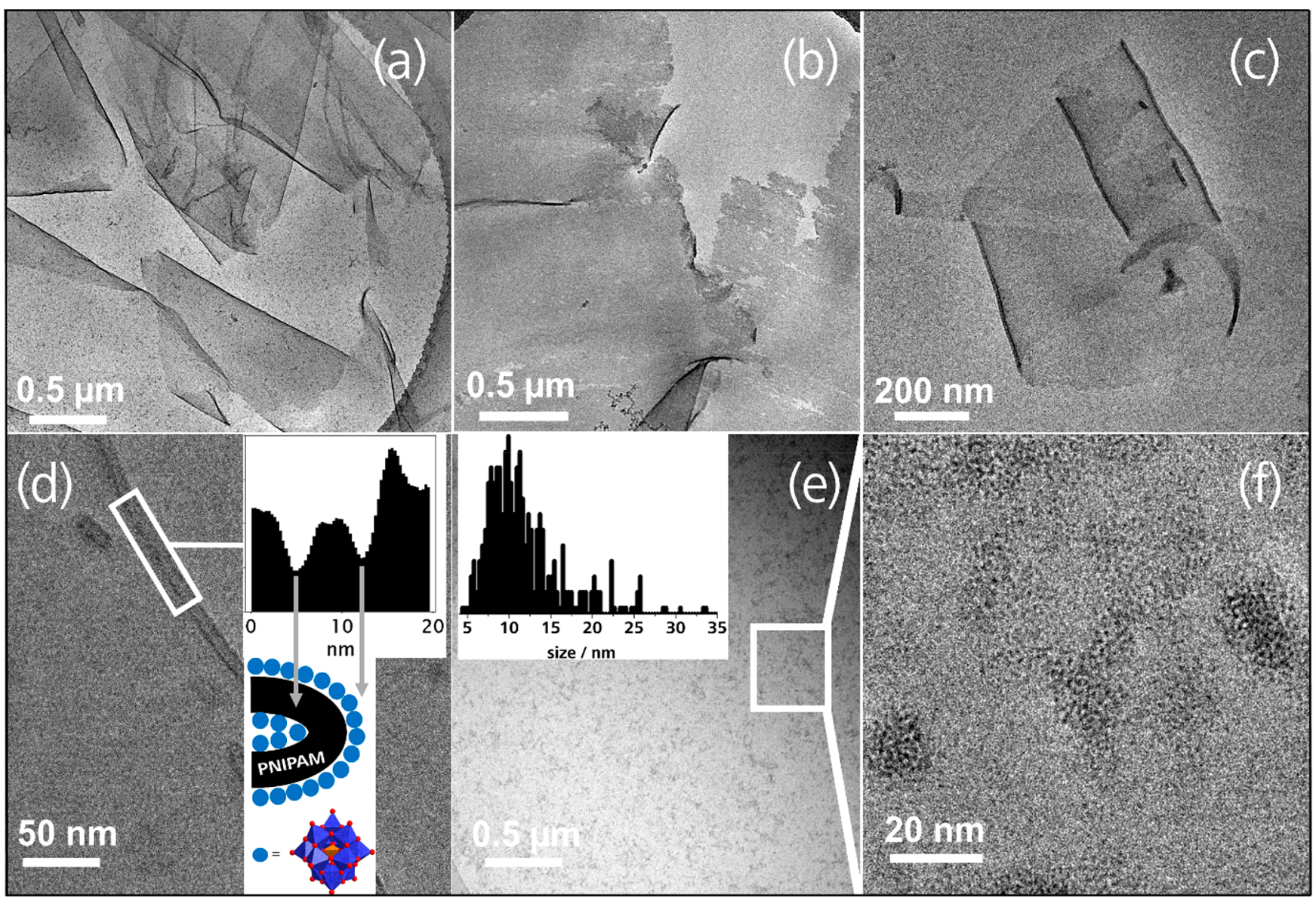

Figure 2. Cryo-TEM micrographs of mixtures containing $1 \mathrm{mM}$ PNIPAM10000 and $5 \mathrm{mM}$ of PW: (a) PNIPAM10000/PW sheets, (b) disrupted sheet, ( $\mathrm{c}$ and $\mathrm{d}$ ) the same wrapped sheet at a different scale, the inset in panel $\mathrm{d}$ shows the pixel gray scale integration corresponding to the electron density profile, averaged over the complete white rectangle and along the long axis. An excess in electron density with a width of around $1.5 \pm 0.5$ $\mathrm{nm}$ is observed at the edges of the sheet and corresponds to a layer of PW clusters; (e) the addition of $100 \mathrm{mM} \mathrm{NaCl}$ shows no sheets but PNIPAM10000/PW globules with a quite large size distribution and a maximum at around $10 \mathrm{~nm}$, the graph shows the size repartition obtained from image analysis treatment, (f) zoom on PNIPAM/PW globules depicted in panel e, the dark black dots have an average size of $1 \mathrm{~nm}$ and correspond to a single PW cluster. All samples were prepared at $25{ }^{\circ} \mathrm{C}$ and then frozen in liquid ethane. The dark edges in the corners of the micrographs ( $a, b$ and e) correspond to the cryo-TEM-grid.

A macroscopic liquid-liquid phase separation appears with time, see Figure S2, which is in agreement with the formation of large structures settling down. This bottom liquid phase is a POM- and PNIPAM-rich phase which shows no precipitate, i.e. it shows no Bragg peaks in SAXS. This liquid-liquid phase separation appears within minute or day time scales depending on PW concentration, the higher the PW concentration the faster the phase separation.

Cryo-TEM on a sample containing $1 \mathrm{mM}$ PNIPAM10000 and $5 \mathrm{mM}$ PW revealed the presence of large sheets with a micrometric size, see Figure $2 \mathrm{a}$. It should be noted that no aggregates could be detected for solutions containing either 1 $\mathrm{mM}$ PW or $1 \mathrm{mM}$ PNIPAM10000. Indeed, PNIPAM produces a too weak electron density contrast to water and PW is too small $(\sim 1 \mathrm{~nm})$ to be detected unambiguously in cryo-TEM, beside its very high electron density compared to water. For PW/PNIPAM mixtures with lower PW contents $(<5 \mathrm{mM})$, for example $1 \mathrm{mM}$ PW/1 mM PNIPAM, neither sheet nor other $\mathrm{nm}$-sized objects were detected. This indicates that the blueish shade observed in PW/PNIPAM mixtures for $c(\mathrm{PW})>5 \mathrm{mM}$, arises from the scattering of light by large sheets composed of PW and PNIPAM.
The sheets appear to be fragile and flexible because some disrupted sheets, i.e. ripped in small pieces, see Figure $2 b$, and bended or enrolled sheets are observed, see Figure $2 \mathrm{c}$,d. It should be noted that the ruptures of the sheets may happen during the sample preparation due to the harsh experimental conditions, see Experimental section. However, the micrograph in Figure $2 \mathrm{~b}$ may also suggest that the sheets consist of distinct subunits. The formation of large aggregates is confirmed by ${ }^{1} \mathrm{H}$ NMR, which shows a strong decrease and broadening of the PNIPAM resonance signals by increasing the concentration of PW from 0 to $10 \mathrm{mM}$, see Figure S3.

Information on the internal structure and on the thickness of the sheets can be obtained from the gray scale profile in the zones of the pictures where the sheets are folded, see Figure $2 \mathrm{~d}$. The gray scale profile is related to the transmission of the electron beam through the sample and informs therefore on local changes in electron density. The averaged integration along the entire length of the white rectangle from left to right in Figure $2 \mathrm{~d}$ yields an electron density profile showing (i) an excess electron density at the edges of the sheets which has around the size of PW $(1 \mathrm{~nm})$ and (ii) the internal area of the sheets with low electron density $(\sim 8 \mathrm{~nm})$ which presumably contains the PNIPAM polymers. Therefore, these results 

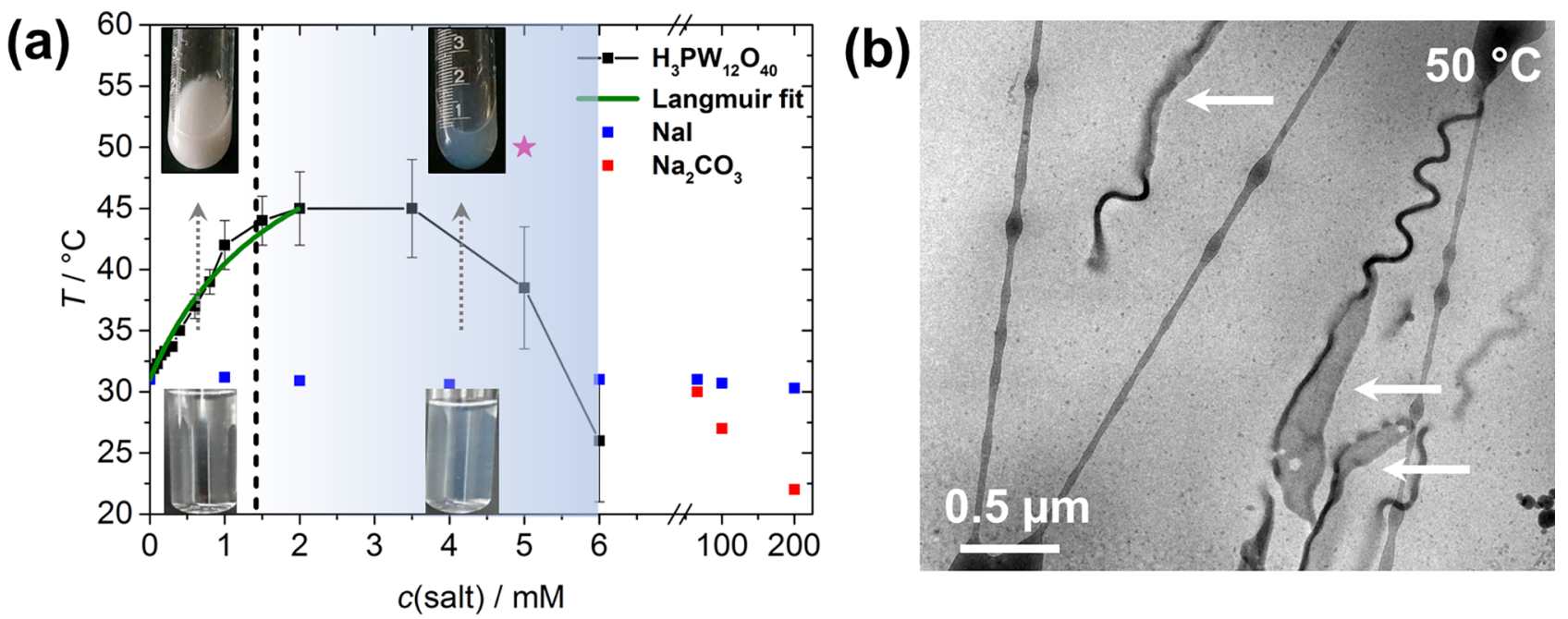

Figure 3. (a) LCST of $1 \mathrm{mM}$ PNIPAM10000 plotted as a function of PW concentration from 0 to $6 \mathrm{mM}$ (dark squares) and of the concentration of classical kosmotrope and chaotrope salts, respectively $\mathrm{Na}_{2} \mathrm{CO}_{3}$ (red squares) and $\mathrm{NaI}$ (blue squares). Error bars represent the error on the LCST for PW determined by visual inspection. Pictures of samples containing $1 \mathrm{mM}$ PNIPAM with 1 and $5 \mathrm{mM}$ PW (left and right) at 25 and $50{ }^{\circ} \mathrm{C}$ (bottom and top) are inset. (b) Cryo-TEM micrograph of a solution containing $1 \mathrm{mM}$ PNIPAM10000-5 mM PW prepared at $50{ }^{\circ} \mathrm{C}$ (composition marked with a pink star in panel a. The light gray stripes correspond to the TEM-sample grid and the worm-like enrolled sheets stem from PNIPAM/PW assemblies. The white arrows point at the partially unfolded sheets, constituting the worm-like structures.

suggest that the sheets are formed by PNIPAM polymers entrapped by two regions where PW accumulates.

Addition of $100 \mathrm{mM} \mathrm{NaCl}$ leads (i) to the full destruction of the sheets associated with the disappearance of the blueish shade of the sample and (ii) to the formation of globular structures with an average size of $10 \mathrm{~nm}$, see Figure 2e,f. Therefore, the sheets are stabilized by electrostatic repulsions arising from the PW anions adsorbed on the PNIPAM polymers. Addition of salt screens these electrostatic repulsions which stabilize the sheet structure. The presence of small dark spots of around $1 \mathrm{~nm}$ in size in the globules, see Figure 3f, indicates that PW anions are inside and/or at the surface of the PNIPAM globules.

The strong interactions between PW and PNIPAM10000, highlighted here by the formation of supramolecular sheets and globular structures, were further investigated by measuring the LCST of PNIPAM as a function of $c(\mathrm{PW})$, see Figure 3a. An increase in the LCST of PNIPAM10000 from 31 to $45{ }^{\circ} \mathrm{C}$ was observed for $c$ (PW) up to around $2 \mathrm{mM}$. The absolute cloud point (CP) increase of $1 \mathrm{mM}$ PNIPAM10000 by PW $(\sim 14$ ${ }^{\circ} \mathrm{C}$ ) is much more pronounced than the effect of a classical chaotropic anion on the CP of $1 \mathrm{mM}$ PNIPAM10000, see for example $\mathrm{I}^{-}$in Figure 3a (blue symbols) or cf. the works of Cremer et al. ${ }^{4,10-13,15}$ This strong difference with classical chaotropes highlights the superchaotropic nature of POMs toward PNIPAM. Moreover, the CP increase takes place at much lower PW concentrations (in the $\mathrm{mM}$ range) than for classical chaotropic anions (in the $M$ range). This is reflected in the large difference in the adsorption constants obtained for $\mathrm{SCN}^{-}, K_{\mathrm{A}}\left(\mathrm{SCN}^{-}\right)=4.3 \mathrm{M}^{-1}$ (determined with PNIPAM170000 from Cremer's work $)^{15}$ and $K_{\mathrm{A}}(\mathrm{PW})=2.1$ $\mathrm{mM}^{-1}$ (determined with PNIPAM10000) obtained from a simple fit of the CP evolution using a Langmuir isotherm model as proposed by Cremer et al., see Figure 3a (green line). ${ }^{15}$ For higher PW concentrations the LCST becomes nearly constant between 2 and $3.5 \mathrm{mM}$ and then strongly decreases above $3.5 \mathrm{mM}$. It is noteworthy that the blueish shade in the solutions appears in this PW concentration range where the LCST stops to increase. Therefore, the uncertainty on the LCST determination becomes larger, up to $\pm 5{ }^{\circ} \mathrm{C}$, by increasing $c(\mathrm{PW})$ above $2 \mathrm{mM}$.

Effect of Temperature. Cryo-TEM micrographs were also recorded for a solution containing $1 \mathrm{mM}$ PNIPAM10000-5 $\mathrm{mM} \mathrm{PW}$ above its $\mathrm{CP}$ at $50{ }^{\circ} \mathrm{C}$, see Figure $3 \mathrm{~b}$. The micrographs show long $(>\mu \mathrm{m})$ worm-like objects with (i) approximately $30 \mathrm{~nm}$ diameter and with (ii) very low transmission of the electron beam indicating that PW anions are tightly condensed inside the "worms". On some regions in the cryo-TEM pictures the worm-like structures, see arrows in Figure $3 b$, appear as they are composed of winded or twisted sheets, which show a comparable aspect and contrast compared to the sheets formed at $25{ }^{\circ} \mathrm{C}$, see Figure 2a. Therefore, the PNIPAM involved in the sheet formation still show thermo-responsivity that lead to the enrolling of the sheets by increasing temperature above the LCST.

The term LCST is here ambiguous as the phase transition determined for PNIPAM in the presence of PW seems to be influenced by the supramolecular self-assembly of PNIPAM and PW, in comparison to molecularly dissolved PNIPAMs in water in the absence of PW. Indeed, the successive salting-in and salting-out behavior by PW addition is shown to be related to the formation of micrometric supramolecular sheets. The phase separation of PNIPAM in the presence of PW is then associated with the aggregation/settling down upon dehydration of the supramolecular structures (here enrolled sheets).

The effect of temperature on PNIPAM/PW mixtures was further investigated by DSC on a $2 \mathrm{mM}$ PNIPAM10000 solution with increasing $\mathrm{PW}$ concentration up to $2 \mathrm{mM}$, see Figure S4. PNIPAM in pure water shows an endothermic peak upon heating which is related to the liquid-liquid phase separation concomitant with the dehydration of the PNIPAM, Figure S4a. ${ }^{2}$ Addition of PW up to $2 \mathrm{mM}$ leads to (i) a shift of the peak to higher temperatures as expected from the increase in the LCST and (ii) the endothermic peak becomes smaller and broader, see Figure S4a-c. The decrease in the area of the peak, which is proportional to the PNIPAM dehydration 
1 mM PNIPAM10000 - 10 mM PW ${ }^{3-}$

$1 \mathrm{mM}$ PNIPAM10000 - 5 mM PW3-
1 mM PNIPAM10000 - 1 mM PW PW $^{3-} 100 \mathrm{mM} \mathrm{NaCl}$ $1 \mathrm{mM}$ PNIPAM 10000 - 1 mM PW3-
$5 \mathrm{mM} \mathrm{PW}^{3-}$

1 mM PNIPAM10000
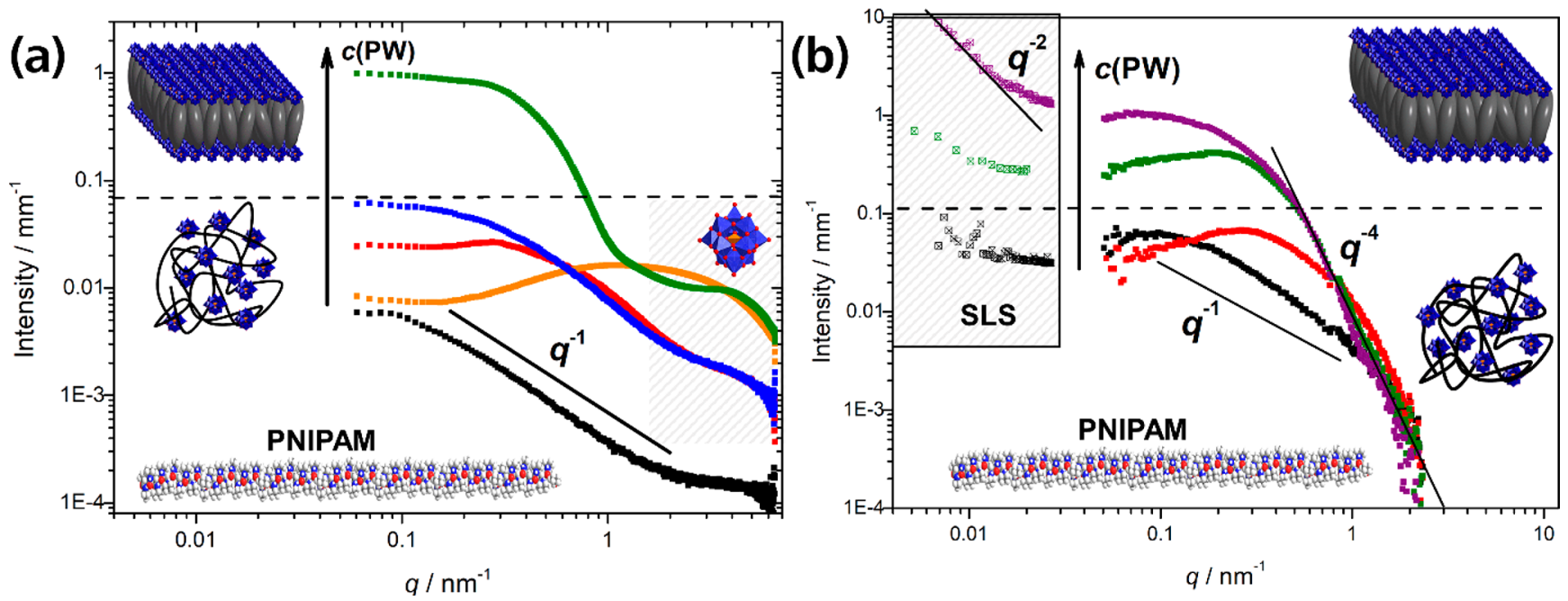

Figure 4. (a) SAXS spectra of $1 \mathrm{mM}$ PNIPAM10000, $5 \mathrm{mM}$ PW and mixtures of $1 \mathrm{mM}$ PNIPAM10000 with PW. (b) SANS spectra of $1 \mathrm{mM}$ PNIPAM10000 in the presence of different concentrations of PW. The inset shows the SLS spectra of 1 mM PNIPAM10000 with various concentrations of PW. The measurements were conducted at $21^{\circ} \mathrm{C}$.

enthalpy, indicates that PNIPAM is less hydrated in the presence of PW. This is in agreement with previous results where it was proposed that the general propensity of POMs to adsorb on hydrated surfaces (here PNIPAM), i.e. the superchaotropic behavior, originates from the partial dehydration of the polar surface and of the POMs. ${ }^{22,24,30}$ Indeed, upon adsorption of nanometer sized ions on PNIPAM polymers many water molecules are released to the water bulk phase. The dehydration process of nanoions has a much weaker enthalpic cost compared to classical (smaller) chaotropic ions (e.g., $\mathrm{SCN}^{-}$), due to the much lower charge density of nanoions (e.g., around $6.5 e^{-} / \mathrm{nm}^{3}$ for $\left.\mathrm{PW}\right)^{24}$ compared for example to $\mathrm{SCN}^{-}\left(\gg 10 e^{-} / \mathrm{nm}^{3}\right)$. Therefore, DSC measurements suggest here that PNIPAM polymers overcome partial dehydration by adsorption of PW, which is consistent with the formation PNIPAM/PW assemblies as observed by cryo-TEM and scattering techniques (see below).

SAXS/SANS Scattering Experiments. SAXS/SANS analyses were performed to obtain further structural information on PNIPAM/PW mesoscale structures, see Figure $4 \mathrm{a}, \mathrm{b}$. The accessible wave vector ( $q$-range) in SAXS (SANS) was $0.1-10 \mathrm{~nm}^{-1}\left(0.05-3 \mathrm{~nm}^{-1}\right)$ which corresponds in real space to a typical size ranging from 0.6 to $60 \mathrm{~nm}$ (2 to 120 $\mathrm{nm})$. The advantage of combining SAXS/SANS scattering experiments arises from the different contrasts of POM and PNIPAM with the solvent, $\mathrm{H}_{2} \mathrm{O}$ or $\mathrm{D}_{2} \mathrm{O}$ for SAXS and SANS, respectively. Indeed, the very high electron density of POM, due to the presence of heavy metals ( $\mathrm{W}$ or Mo) in their structures, leads to a high contrast against water $\left(\mathrm{H}_{2} \mathrm{O}\right.$ or $\mathrm{D}_{2} \mathrm{O}$ ) or against PNIPAM in SAXS, see Table S1. On the contrary in SANS, PNIPAM has a high contrast to deuterated water due to the large difference in the scattering length densities (SLDs) between hydrogen atoms of PNIPAM and deuterium atoms of $\mathrm{D}_{2} \mathrm{O}$, whereas POMs have nearly the same SLDs as $\mathrm{D}_{2} \mathrm{O}$, i.e. it shows nearly no contrast against $\mathrm{D}_{2} \mathrm{O}$. Therefore, POM and PNIPAM are nearly transparent in SANS and SAXS, respectively, making these two techniques complementary for the investigation of mesoscale structures composed of POM and PNIPAM in (heavy) water. In addition to SAXS/SANS measurements, static light scattering experiments, whose contrast arises from the difference in refractive indexes between the PNIPAM/PW aggregates and water, was used to reach a lower $q$-range, 0.007 to $0.03 \mathrm{~nm}^{-1}$ corresponding to $210-900 \mathrm{~nm}$ in real space.

In Figure 4a, the SAXS spectrum of $1 \mathrm{mM}$ PNIPAM10000 in water shows (i) a very low scattered intensity $(<0.01$ $\mathrm{mm}^{-1}$ ), as expected from its low SLD difference with $\mathrm{H}_{2} \mathrm{O}$, see Table S1, and (ii) a $q^{-1}$ decay, which is also observed in SANS, see Figure $4 \mathrm{~b}$. The $q^{-1}$ dependence observed between 0.2 and $1 \mathrm{~nm}^{-1}$ informs on the presence of a $1 \mathrm{D}$ structure (e.g., rod, cylinder, ...), in a length scale from 6 to $30 \mathrm{~nm}$, and it suggests therefore that PNIPAM10000 is in a straight fully extended (hydrated) conformation in water. This is in agreement with molecular dynamics (MD)-simulations performed by Du et al., who showed that PNIPAM is present in an extended conformation in an aqueous environment below its LCST. ${ }^{6}$ Moreover, it is further supported by the fact that the length of a fully extended PNIPAM10000 polymer with 88 repeating units is around $25 \mathrm{~nm}$ which is comparable to the maximum length of the $1 \mathrm{D}$ structure deduced from the minimum $q$-value of the $q^{-1}$ decay, i.e. around $30 \mathrm{~nm}$. In the SANS spectrum, a $q^{-1}$ dependence is also observed in the same $q$-range, see Figure $4 \mathrm{~b}$ dark symbols. The level of the absolute scattered intensity at low $q$-values, i.e. $\lim _{q \rightarrow 0} I(q)$, the so-called forward scattering, was used to evaluate if PNIPAM is aggregated in solution, see the calculation in SI. An average aggregation number of 1.4 was calculated, with an error estimated to be around 0.5 . Hence, we can conclude here that PNIPAM10000 polymers adopt an extended conformation in water (at $21^{\circ} \mathrm{C}$ ) and are mostly present in "monomeric" form, i.e. nonaggregated.

In SAXS, PW provides a much stronger scattered intensity compared to PNIPAM, and shows the typical SAXS pattern obtained for spherical scattering objects with a radius of 0.45 $\mathrm{nm}$, i.e. close to the average crystal radius of PW, see for 
example the spectrum obtained for $5 \mathrm{mM}$ PW in Figure 4a (orange symbols). ${ }^{22}$ The decrease in the scattered intensity for $q<0.8 \mathrm{~nm}^{-1}$ arises from electrostatic repulsions between PW anions. $^{42}$ In comparison to aqueous solutions containing only PW, PNIPAM-PW mixtures show large excess scattering below $2 \mathrm{~nm}^{-1}$, see Figure $4 \mathrm{a}$ (red, blue and green symbols) and Figure S5. This excess scattering is due to the presence of much larger scattering objects containing PW anions, i.e. here globules or sheets depending on PW concentration as inferred from the cryo-TEM pictures.

For PW concentrations below $5 \mathrm{mM}$, e.g. for $1 \mathrm{mM}$ PNIPAM10000-1 mM PW where no sheets were observed, see Figure 4a (red symbols), the SAXS spectra show (i) strong excess scattered intensity for $q$ values below $2 \mathrm{~nm}^{-1}$ indicating the presence of scattering objects with a size of some $\mathrm{nm}$ and containing PW, i.e. globules (see below) and (ii) a decrease in the scattered intensity for $q<0.3 \mathrm{~nm}^{-1}$ which arises from repulsive interactions between the globules. Upon addition of $100 \mathrm{mM} \mathrm{NaCl}$, the globule-globule repulsion vanishes to give a constant scattering level at low $q$ (blue curve in Figure 4a for $\left.q<0.2-0.3 \mathrm{~nm}^{-1}\right)$, which is typical of the screening of electrostatic repulsions between scattering objects. The scattered intensity, $I(q)$, of isotropically dispersed objects can be expressed as $I(q)=I(0) P(q) S(q)$ where $I(0)$ is the forward scattering, i.e. in the low $q$ limit, $P(q)$ is the form factor of a single scattering object which depends on its shape and size and $S(q)$ is the structure factor which accounts for interparticle interactions. Therefore, in the presence of $100 \mathrm{mM} \mathrm{NaCl}$, globule-globule interactions vanish, i.e. $S(q)_{\text {globules-globules }}=1$, which leads the scattered intensity to depend only on $P(q)$ and $I(0)$. The SAXS spectrum in the presence of salt was fitted by using a Guinier analysis and gave an estimate of the averaged globules radius between $7 \pm 1 \mathrm{~nm}$, see Figure S6. The quality of the Guinier fits is not good which is likely to be due to a high size polydispersity, as observed in cryo-TEM pictures of globules obtained with salt or with PNIPAM2000, see for example Figure $2 \mathrm{f}$ or Figure S7. The number of PW anions in the globules was estimated $(\sim 17 \pm 1)$ by dividing the forward scattered intensities in SAXS, $I_{\mathrm{SAXS}}(0)$, of $1 \mathrm{mM}$ PNIPAM10000-1 mM PW-100 mM NaCl by $1 \mathrm{mM}$ PW-100 $\mathrm{mM} \mathrm{NaCl}$. In this latter calculation it is assumed that the SAXS contrast produced by PNIPAM/water is negligible compared to the $\mathrm{PW} /$ water contrast, see Table S1, and therefore that only PW contributes to the $I(0)$ forward scattering. In addition, the number of PNIPAM polymers per globules $(\sim 3)$ and the radius of the globules, $R=6 \pm 1 \mathrm{~nm}$ (see Guinier analysis of $\operatorname{SANS} / S(q)_{\text {globules-globules }}$ in Figure S6) was estimated by SANS from the spectrum of $1 \mathrm{mM}$ PNIPAM10000-1 mM PW, see Figure $4 \mathrm{~b}$ (red) and Figure S6. In order to obtain some information on the internal structure of the globules, $I(q) / P(q)_{\mathrm{PW}}$ was plotted versus $q$ for the SAXS spectrum of $1 \mathrm{mM}$ PNIPAM-1 mM PW, see Figure S8. This plot shows a broad scattering peak centered at around $6 \mathrm{~nm}^{-1}$, which is attributed to PW-PW correlations inside the globules. Therefore, the peak position enables to estimate the average distance between PWs inside the globules, $d_{\mathrm{PW}-\mathrm{PW}}=$ $2 \pi / q_{\text {peak }} \sim 1.0 \mathrm{~nm}$. This value is close to the diameter of a PW unit $(\sim 0.9-1 \mathrm{~nm})$. So, it can be concluded that PWs are nearly in close packing inside the globules.

As a conclusion, a transition from unaggregated PNIPAM polymers in extended conformation toward globules is observed in SANS/SAXS upon addition of $1 \mathrm{mM}$ PW to a 1 mM PNIPAM10000 solution, see Figure 4a,b from the dark to the red spectrum in SAXS and SANS, respectively. The globules have a spherical shape with around $10 \mathrm{~nm}$ in diameter, independently of the presence of $100 \mathrm{mM} \mathrm{NaCl}$, and they are composed of, on average, 3 PNIPAM10000 polymers (with in average 88 repeating units) and 16-17 PW anions.

A further increase of the PW concentration above $1 \mathrm{mM}$ leads to a sudden onset in the SAXS scattered intensity, which can be attributed to the formation of sheets, see Figure 4 (red to green symbols) and Figure 5. Note that the scattered

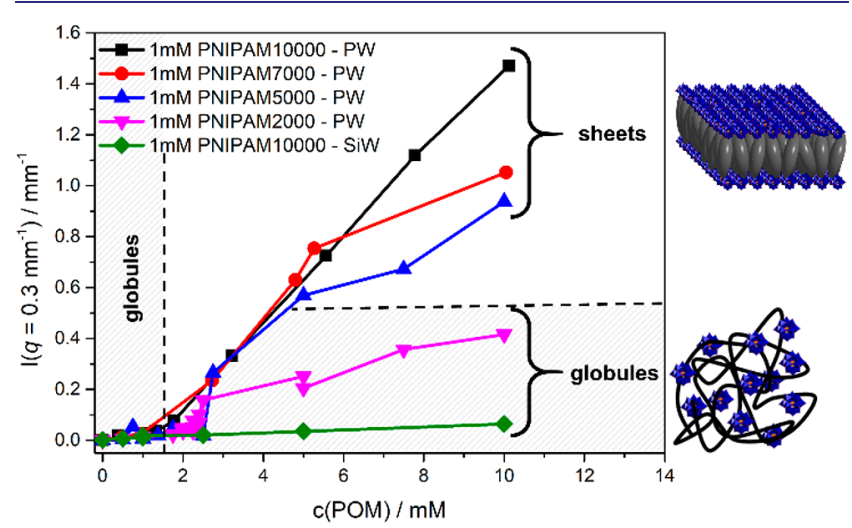

Figure 5. Plot of the SAXS scattered intensity at $q=0.3 \mathrm{~nm}^{-1}$ as a function of $c(\mathrm{POM})$ for $1 \mathrm{mM}$ PNIPAM of different molecular weights: 2000, 5000, 7000, 10000, with PW and PNIPAM10000 with $\mathrm{SiW}$. The measurements were conducted at $21^{\circ} \mathrm{C}$.

intensity is proportional to the square of the volume of scattering objects. As a consequence, an increase in the size of the aggregates results in a significant increase in the scattered intensity (at low $q$ values). The scattered intensity at $q=0.3$ $\mathrm{nm}^{-1}$, which is a $q$-value where globules or sheets scatter significantly more compared to free (unaggregated) PW anions, was plotted as a function of $c(\mathrm{PW})$ in order to estimate the concentration where sheets start to form, see Figure 5. Indeed, this latter representation of the scattering data shows a clear break at $c(\mathrm{PW})=1.4 \mathrm{mM}$, for $1 \mathrm{mM}$ PNIPAM10000 (Figure 5 dark symbol, a zoom of the curve is given in Figure S9), which corresponds to the critical PW concentration of formation of sheets $\left(c_{\mathrm{PW}} \mathrm{Sc}\right)$, i.e. the PW concentration at which the transition from globules to sheets suddenly appears. At higher PW concentrations, at around 5 $\mathrm{mM}$, the blueish shade appears which is supposedly related to an increase in the concentration and/or size of the sheets, as inferred from cryo-TEM. The presence of sheets was confirmed by SLS which shows a $q^{-2}$ dependence as expected for $2 \mathrm{D}$ planar structures for 5 and $10 \mathrm{mM} \mathrm{PW}$ in the presence of $1 \mathrm{mM}$ PNIPAM10000, see Figure $4 \mathrm{~b} .{ }^{43}$ Moreover, it is worth mentioning that in SANS a $q^{-4}$ dependence in the scattered intensity (Porod's regime) is observed for $q>1$ $\mathrm{nm}^{-1}$, see Figure $4 \mathrm{~b}$ (red, green and purple symbols), when globules and sheets are formed indicating a sharp interface in the scattering length density profile, i.e. between the scattering objects (globules/sheets) and the surrounding medium (deuterated water).

Additional information on the PW distribution in the sheets was obtained from SAXS by dividing the scattering spectrum by the form factor of the PW, $P_{\mathrm{PW}}(q)$, see Figure $S 10$ for $1 \mathrm{mM}$ PNIPAM10000-5 mM PW. Such a representation of the SAXS spectrum highlights a broad scattering peak, centered at around $6.2 \mathrm{~nm}^{-1}$, which arises from strong PW-PW 
correlations. This indicates that PW anions are nearly in close contact at the edges of the sheets, where the mean PW-PW distance is around $1.0 \mathrm{~nm}(d=2 \pi / 6.2 \mathrm{~nm}=1.0 \mathrm{~nm})$, which is close to the size of PW (as in the globular state, see above and in Figure S10). However, PW anions are accumulated at the surface of the sheets as inferred from the cryo-TEM pictures, see Figure $2 \mathrm{~d}$, and not buried in the aggregates as in the globules. Therefore, the globule-to-sheet transition implies a molecular reorganization in the aggregates with a partial segregation of PW from the PNIPAM polymer.

The $c_{\mathrm{PW}} \mathrm{Sc}$ value was also estimated for $2 \mathrm{mM}$ PNIPAM10000, i.e. $2.8 \mathrm{mM}$, see Figure S9. Interestingly, the average number of NIPAM units per PW at the globule-sheet transition is constant, i.e. 63 and 64 , for 1 and $2 \mathrm{mM}$ PNIPAM10000, see Table 1 . This suggests that aggregates are

Table 1. Data of PNIPAM Polymers and of PNIPAM/PW Mixtures

\begin{tabular}{|c|c|c|c|c|}
\hline \multirow[b]{2}{*}{$M_{\text {PNIPAM }}(\mathrm{g} / \mathrm{mol})$} & \multicolumn{4}{|c|}{ PNIPAM } \\
\hline & 2000 & 5000 & 7000 & 10000 \\
\hline$n_{\mathrm{NIPAM}}{ }^{a}$ & 18 & 44 & 62 & 88 \\
\hline$L_{\text {PNIPAM }}^{b}(\mathrm{~nm})$ & $\approx 5$ & $\approx 11$ & $\approx 15$ & $\approx 22$ \\
\hline$t_{\text {sheet }}^{c}(\mathrm{~nm})$ & no sheet formation & $\approx 4$ & $\approx 6$ & $\approx 8$ \\
\hline $\mathrm{LCST}_{\max }{ }^{d}\left({ }^{\circ} \mathrm{C}\right)$ & $\begin{array}{l}56.5 \\
(47)\end{array}$ & $\begin{array}{l}41 \\
(37)\end{array}$ & $\begin{array}{l}47 \\
(41)\end{array}$ & $\begin{array}{l}48 \\
(43)\end{array}$ \\
\hline$n_{\mathrm{NIPAM}} / n_{\mathrm{PW}}^{c_{\mathrm{PW}} c_{e}}$ & n.d. & n.d. & $62(65)$ & $\begin{array}{l}63 \\
(64)\end{array}$ \\
\hline$c_{\mathrm{PW}} \mathrm{Sc}^{f}(\mathrm{mM})$ & n.d. & n.d. & $1.0(1.9)$ & $1.4(2.8)$ \\
\hline
\end{tabular}

${ }^{a}$ Average number of NIPAM unit of the polymer. ${ }^{b}$ Average length of the extended polymer; it is assumed that a NIPAM repeating unit in a fully extended conformation is $0.24 \mathrm{~nm}$ long. ${ }^{c}$ Thickness of the sheets defined as the PW center to PW center distance from cryo-TEM images. ${ }^{d} \mathrm{LCST}_{\max }$ is the maximum value of the LCST obtained by addition of PW; the given values correspond to $1 \mathrm{mM}$ PNIPAM $x 000$ $(x=2,5,7,10)$ solutions; and values in brackets correspond to $2 \mathrm{mM}$ PNIPAM $x 000$ solutions. ${ }^{e}$ Molar ratio of total NIPAM units in the system per PW at $c_{\mathrm{PW}} \mathrm{sc}$. ${ }^{f}$ Critical $\mathrm{PW}$ concentration for sheet formation, n.d. means "not determined" because the scattering data was not of sufficient quality.

controlled by an overall PW/PNIPAM stoichiometry and that the PW/PNIPAM10000 adsorption constant is strong enough to neglect free PW and PNIPAM in solution at least in the $\mathrm{mM}$ range.

Effect of the PNIPAM Chain Length on the SelfAssembly. The effect of PNIPAM chain length on the selfassembly with PW was investigated by using PNIPAM2000, 5000 and 7000, respectively with in average 18, 44 and 62 NIPAM repeating units, with an experimental approach similar to the one used for PNIPAM10000, i.e. combining SAXS/ SANS, LCST evolution and cryo-TEM. The formation of sheets was observed with PNIPAM 5000 and 7000 but not for PNIPAM2000, for which only (5-20 nm size) globules could be observed, see cryo-TEM pictures in Figure S7. Interestingly the SAXS spectra obtained with PNIPAM2000 $1 \mathrm{mM}$, see Figure S11, by increasing the PW concentration show a sudden increase at around $2 \mathrm{mM}$ of PW (pink symbols in Figure 5), which is likely to correspond to the formation of the globules observed in cryo-TEM, see Figure S7. As a consequence, it seems that a minimum length for PNIPAM, ranging between 18 and 44 repeating units, is required for the formation of sheets. Interestingly the thickness of the sheets, as determined by cryo-TEM depends nearly linearly on the PNIPAM molar mass (or length), see Figure 6 and Table 1. The sheet thicknesses are in average 4, 6 and $8 \mathrm{~nm}$ for PNIPAM5000,

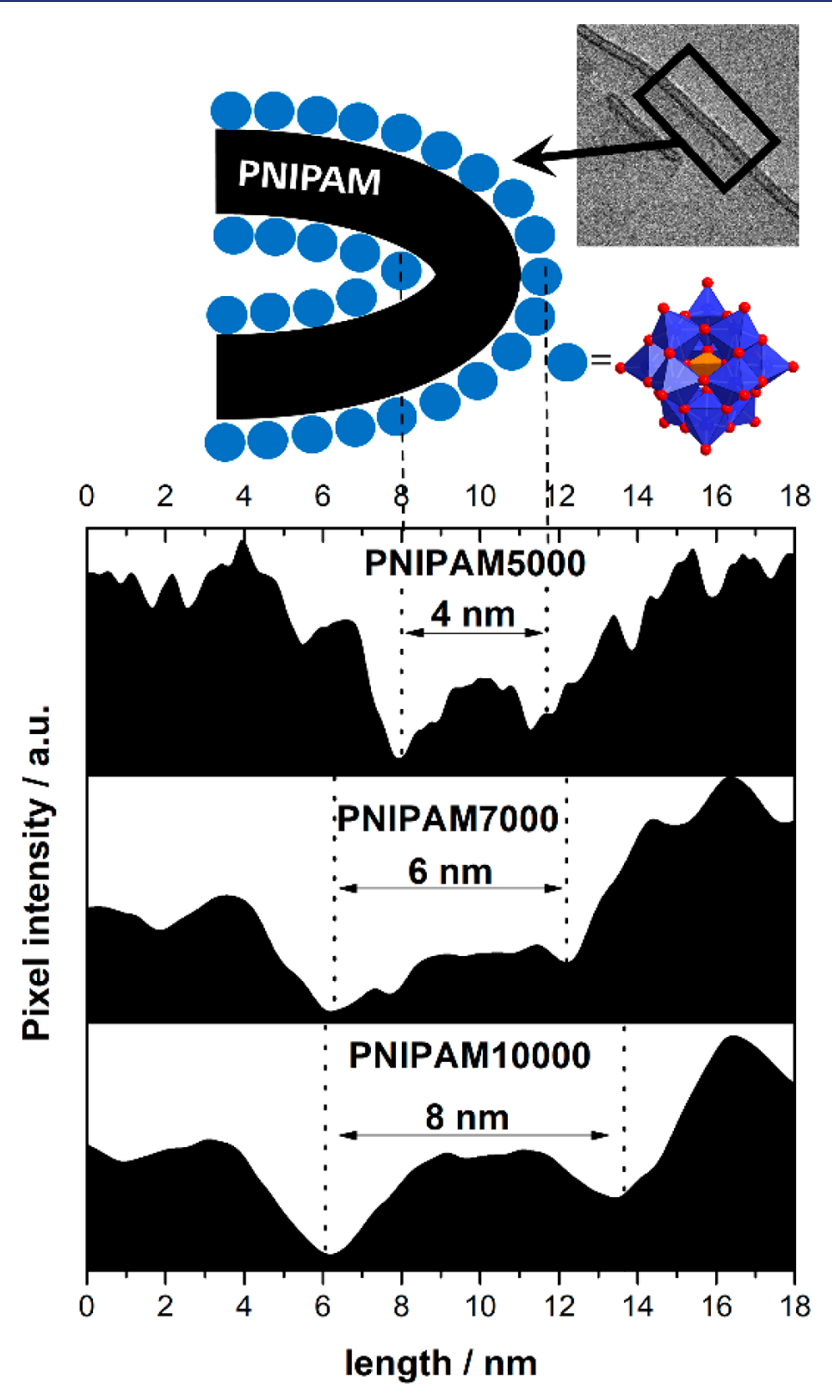

Figure 6. Influence of the PNIPAM chain length on the sheet thickness obtained with PW and PNIPAM5000, PNIPAM7000 and PNIPAM10000. The graph depicts the pixel gray scale integration corresponding to the electron density profile extracted from cryoTEM image at the edge of a wrapped sheet.

7000 and 10000, respectively, which are significantly lower compared to the average fully extended length of the corresponding PNIPAM ( $\left.L_{\text {PNIPAM }}\right)$, see in Table 1 . This suggests that the PNIPAM chains have a coil/globular conformation inside the sheets, as expected for partially dehydrated PNIPAM chains subsequent to the adsorption of PW. PNIPAM chains remain at least partially hydrated in the sheets as inferred from the temperature sensitivity, see Figure $3 a$. The SAXS pattern evolution of solutions containing $1 \mathrm{mM}$ PNIPAM $x 000(x=5,7)$ in the presence of PW $(0<c(\mathrm{PW})<$ $10 \mathrm{mM})$, see Figures $\mathrm{S} 12$ and $\mathrm{S} 13$, are very similar to the scattering patterns with $1 \mathrm{mM}$ PNIPAM10000, see Figure 4a. Indeed, a sudden onset in the scattered intensity (at $0.3 \mathrm{~nm}^{-1}$ ) is observed at critical PW concentrations, which are attributed to concentrations where sheets form $\left(\mathrm{c}_{\mathrm{PW}} \mathrm{sc}\right)$, see Figure 5 and Figures S11-S17.

Some attempts were made to correlate the experimental data, e.g. sheet thickness, $\mathrm{c}_{\mathrm{PW}} \mathrm{Sc}$, with the different features of 
the systems, e.g. polymers length, total number of nipam units at the $\mathrm{c}_{\mathrm{PW}} \mathrm{Sc}$ or at the $\mathrm{LCST}_{\max }$ values are listed in Table 1 and S1. Interestingly, it seems that the formation of sheets for PNIPAM10000 and 5000 appears at a critical and constant number of NIPAM units per PW, $n_{\mathrm{NIPAM}} / n_{\mathrm{PW}}^{{ }_{\mathrm{C} W W}}=62-65$, i.e. below this limit sheets form.

Effect of the Nature of the POM on the Self-Assembly with PNIPAM. The effect of the POM composition and charge on PNIPAM10000 was also investigated in order to expand the understanding of the PNIPAM-POM selfassembly process with respect to the super chaotropic behavior of POMs. $\mathrm{PMo}_{12} \mathrm{O}_{40}{ }^{3-}(\mathrm{PMo})$ and $\mathrm{SiW}_{12} \mathrm{O}_{40}{ }^{4-}(\mathrm{SiW})$ were compared to $\mathrm{PW}_{12} \mathrm{O}_{40}{ }^{3-}$ in order to investigate respectively (i) the role of the POM polarizability, i.e. PMo has much less electrons than PW and has therefore a much lower polarizability, and (ii) charge density.

As for PW, cryo-TEM shows the formation of sheets for PMo/PNIPAM10000 mixtures and SAXS spectra of PNIPAM10000 with increasing concentrations of PMo show a similar evolution of the scattered intensity compared to the system with PW. However, PMo and PMo/PNIPAM aggregates produce lower scattered intensities as expected from the lower SLD of PMo compared to PW, see Figure S18 and Table S1. The critical PMo concentration of formation of sheets $\left(c_{\mathrm{PMo}} \mathrm{sc}\right)$ appears at $1.9 \mathrm{mM}$, compared to $1.4 \mathrm{mM}$ for $\mathrm{PW}$, indicating that a higher concentration of PMo is required, compared to $\mathrm{PW}$, to reach the transition from the globules to the sheets, see Figure S19. Therefore, the decrease in the POM polarizability from $\mathrm{PW}_{12} \mathrm{O}_{40}{ }^{3-}$ to $\mathrm{PMo}_{12} \mathrm{O}_{40}{ }^{3-}$ has a slight influence on the sheet formation, as previously concluded. ${ }^{22,24}$ This effect is related to the superchaotropic behavior of the POMs and, as it is usually discussed for classical Hofmeister anions, the higher the anion polarizability the stronger the affinity of the chaotropic anion for hydrated surfaces. ${ }^{22}$

For SiW, the self-assembly of PNIPAM10000 is very much different compared to PW (or PMo). Previously, it has been observed that SiW and PW have different physicochemical behaviors in water, mainly regarding their propensity (i) to adsorb to surfaces and (ii) to self-assemble, see the discussion below. $^{42,44,45}$ No blueish shade, which is associated with the formation of the large sheets with PW, was observed in the samples up to $c(\mathrm{SiW})=10 \mathrm{mM}$. SLS measurements also did not indicate the presence of large objects and SAXS did not show any sudden onset in the scattered intensity by adding SiW. Instead, a linear increase in the scattered intensity is observed as a function of SiW concentration (see Figure 5 green curve and Figure S20). The general shape of the SAXS spectra, in the lower $q$-range $\left(q<1 \mathrm{~nm}^{-1}\right)$, informs on the formation of large (globular) scattering objects with repulsive interactions at $\mathrm{SiW}$ concentrations as low as $0.5 \mathrm{mM}$, see Figure S20. The addition of $\mathrm{NaCl}$ leads to the screening of electrostatic repulsions between the globules, see the spectrum of $1 \mathrm{mM}$ PNIPAM10000/1 mM SiW with $100 \mathrm{mM} \mathrm{NaCl}$, see Figure S20 and Figure S21, and enables the estimation of (i) the globule size from a Guinier fit $(R=11.9 \mathrm{~nm}$, see Figure S21) and (ii) number of SiW in the globules $17 \pm 1$. Therefore, addition of SiW up to $10 \mathrm{mM}$ only leads to the formation of SiW/PNIPAM globules and no transition toward sheets was observed.

It is worth mentioning that for all systems investigated here, the globules are observed already at low POM concentrations, i.e. $c(\mathrm{POM})<0.1-1 \mathrm{mM}$. Therefore, the POM concentration where globules start to form could not be estimated because it is too low. This indicates that the POM/PNIPAM adsorption constant is strong, i.e. at least in the $\mathrm{mM}^{-1}$ range.

In a previous contribution, we have shown that the charge density of POMs was the main parameter contributing to their superchaotropic behavior by measuring the evolution of the cloud point of a nonionic polyethoxylated surfactant by addition of different POMs: the higher the charge density the weaker the chaotropic effect, i.e. the weaker the POMs adsorb at hydrated surfaces. ${ }^{24}$ Therefore, SiW is expected to interact less with PNIPAM than PW. This general tendency is also reflected here in the increase in the LCST of PNIPAM10000 by adding POM, which is more pronounced for PW than SiW, see Figure S22.

The origin of the difference in the ability of the POMs, between PW (or PMo) and SiW, to form sheet is still unclear. However, it may be noted that SiW brings 4 electrical charges, compared to 3 for PW. As a consequence, stronger POMPOM electrostatic repulsions between the globules are expected for SiW compared to PW. Therefore, such strong repulsions interactions for SiW/PNIPAM globules could possibly prevent the phase transition from globules to sheets.

Interestingly, the SAXS spectra for $1 \mathrm{mM}$ PNIPAM10000 with $\mathrm{SiW}$ show the presence of a broad peak at an intermediate $q$-range $\left(0.2-0.7 \mathrm{~nm}^{-1}\right)$ shifting from low to high $q$-values by increasing $\mathrm{SiW}$ concentration, see black arrows in Figure S20. Such a peak is not (or not clearly) visible in the PW/PNIPAM spectra, see Figures $4 \mathrm{a}$ and S5. This broad peak is attributed to SiW-SiW repulsive interactions in the globules and its position informs on the average $\mathrm{SiW}-\mathrm{SiW}$ distanc, which decreases from approximately 30 to $9 \mathrm{~nm}, d_{\mathrm{SiW}-\mathrm{SiW}}=2 \pi / q_{\text {peak }}$, increasing $\mathrm{SiW}$ concentration. A log-log plot of the SiW-SiW distance as a function of the $\mathrm{SiW}$ volume fraction shows a linear dependence with a slope (exponent) very close to $-1 / 3$, which is the value expected for the isotropic dilution of objects (3D dilution), see Figure S23 for the details on the dilution law. Therefore, it can be concluded that SiW units are isotropically distributed inside the globules. This peak is only visible in the spectra in the abscence of salt. Indeed, the peak vanishes by addition of salt which induces the screening of the electrostatic repulsions between the globules; see the spectra of $1 \mathrm{mM}$ PNIPAM10000/1 mM SiW without and with $100 \mathrm{mM}$ $\mathrm{NaCl}$ in Figure S20 (green and black symbols, respectively). The isotropic distribution of $\mathrm{SiW}$ units inside the globules suggests that the globules are in a liquid state and at thermodynamic equilibrium.

A fundamental difference is observed here between PW (PMo) and SiW regarding their ability to form PNIPAM sheets. Some works have recently highlighted that SiW and PW have different physicochemical behaviors, regarding their propensity (i) to adsorb to surfaces and (ii) to selfassemble. $^{42,44,45}$ Indeed, PW shows a general tendency for self-assembly in water, i.e. to form clusters or fractal-like aggregates, $^{42,45}$ and to adsorb to the water-air surface ${ }^{44}$ (at rather high concentrations, above around $70 \mathrm{mM}$, compared to classical surface active molecules such as surfactants) whereas $\mathrm{SiW}$ is only present in monomeric state in bulk water. Besides that PW does not affect significantly the surface tension of water, ${ }^{44}$ it has been shown, by combining X-ray reflectivity and grazing incidence-SAXS (GiSAXS), that PW in its acidic form, i.e. $\mathrm{H}_{3} \mathrm{PW}_{12} \mathrm{O}_{40}$, adsorbs at the water-air interface, at relatively high concentrations $(90 \mathrm{mM})$. Moreover, GiSAXS has revealed the presence of two characteristic PW-PW distances (1.25 and $1.77 \mathrm{~nm}$ ) at the water-air surface which were compared to 
distances found in the HPW crystal structure. It was proposed that the Zundel ion, $\mathrm{H}_{5} \mathrm{O}_{2}^{+}\left(\mathrm{H}_{3} \mathrm{O}^{+} \ldots \mathrm{OH}_{2}\right)$, could be involved in the surface activity of PW by intercalating between PW anions. ${ }^{44}$ On the contrary, such an arrangement is not possible with $\mathrm{SiW}$ which does not show adsorption at the air-water interface. ${ }^{44}$ The crystal-like structure of PW anions at interface implies that the counterion $\left(\mathrm{H}_{5} \mathrm{O}_{2}^{+}\right)$binding is strong otherwise electrostatic repulsions between $\mathrm{PW}$ anions at such short distances would be too high. Therefore, the counterion binding decreases efficiently PW-PW electrostatic repulsions which may subsequently promote adsorption of PW at the water-air surface. It may also suggest here that the formation of sheets observed with PW and PNIPAM arises from a general ability of PW to form 2D layers such as observed at the waterair interface.

It was shown above that addition of $100 \mathrm{mM} \mathrm{NaCl}$ to POM/PNIPAM sheets leads to the disruption of the sheets, see Figure 2e,f. Based on the discussion above, such a strong effect of salt addition may either come from (i) a screening effect of the PW-PW electrostatic interactions if the sheets are stabilized by repulsive interactions or from (ii) an ionexchange of the Zundel ion by sodium (from $\mathrm{NaCl}$ ) which would also destabilize the sheets. As a conclusion here, the origin of sheet formation/disruption with $\mathrm{PW}$ and by salt addition is still unclear and some further investigations need to be conducted to decipher the exact mechanism. Nevertheless, it should be noted that PW has a general propensity to form 2D layered arrangements, e.g. self-assembled nanostructure dimensions in molecular Janus particles, ${ }^{46} 2 \mathrm{D}$-crystallization of POM-based surfactants, ${ }^{37,47} 2 \mathrm{D}$ hexagonal nanostructures ${ }^{39}$ or the layered packing of $\mathrm{PW}_{12} \mathrm{O}_{40}{ }^{3-}$ in PEG/POM based hybrid crystals, ${ }^{23}$ compared to SiW. Consequently, it seems here that the tendency of PW to form $2 \mathrm{D}$ structures promotes the formation of PNIPAM sheets.

\section{CONCLUSION}

Keggin's POMs, here $\mathrm{H}_{3} \mathrm{PW}_{12} \mathrm{O}_{40}, \mathrm{H}_{3} \mathrm{PMo}_{12} \mathrm{O}_{40}$ and $\mathrm{H}_{4} \mathrm{SiW}_{12} \mathrm{O}_{40}$, strongly adsorb on short chain PNIPAM polymers (PNIPAM $x 000$, with $x=2,5,7,10$ ), and this adsorption leads to a strong increase in the clouding temperature of PNIPAM. The general property of POMs to adsorb to neutral hydrated surfaces, e.g. nonionic micellar surfaces, or to form assemblies with hydrophilic neutral oligomers (e.g., polyethylene glycol) or macrocyclic molecules (e.g., cyclodextrins), was highlighted in previous investigations. This effect was referred to as superchaotropy, which appears to be a general property of nanoions with delocalized charges. The adsorption of anionic POMs onto uncharged PNIPAM chain is not driven by pure electrostatic attractions but it results from the superchaotropic effect which involves the partial dehydration of both the PNIPAM chains and (weakly hydrated, superchaotropic) POM anions. The increase in the electrical charges of a polymer chain is known to lead to the stretching the polymer chains into a fully extended conformation, as a result of minimization of electrostatic repulsions between the charges carried by the polymer, e.g. with poly acrylic acid when $\mathrm{pH}$ is increased which turns the carboxylic acids $(\mathrm{COOH})$ into the charged carboxylate form $\left(-\mathrm{COO}^{-}\right)$. Here the adsorption of POMs on PNIPAM chains, which grants charges to PNIPAM chains, does not lead to the full stretching of the chains but it induces an assembly process between PNIPAM chains mediated by POMs as a result of their superchaotropic behavior. The adsorption of POMs on
PNIPAM chains leads to the formation of globular objects with an average size of $10 \mathrm{~nm}$ and eventually for PW and PMo to the formation of stimuli responsive (salt and temperature stimulus) micrometric sheets (with $\mathrm{nm}$ thickness) via selfassembly of PNIPAMx000 $(x=5,7,10)$. As proposed by Nau and Assaf in a recent review, ${ }^{26}$ it is likely that the concept presented here, based on the superchaotropy of nanoions, to produce nanostructured materials is general, and can be extended to other superchaotropic nanoions, such as boron clusters (boranes, metallacarboranes, etc.) ${ }^{30,48}$ and to other hydrophilic polymers, such as polyethylene glycols as previously demonstrated. $^{23}$

\section{ASSOCIATED CONTENT}

\section{Supporting Information}

The Supporting Information is available free of charge on the ACS Publications website at DOI: 10.1021/jacs.8b12181.

$$
\text { Experimental details (PDF) }
$$

\section{AUTHOR INFORMATION}

\section{Corresponding Author}

*pierre.bauduin@cea.fr

ORCID

Arno Pfitzner: 0000-0001-8653-7439

Pierre Bauduin: 0000-0001-6128-7971

Notes

The authors declare no competing financial interest.

\section{ACKNOWLEDGMENTS}

T.B., A.P., P.B. and O.D. thank the "Bayerisch-Französisches Hochschulzentrum" (BFHZ, grant FK41_15) and the Deutsche Forschungsgemeinschaft (GRK 1626) for financial support. We thank the ESRF for beam time allocation (SC4473) and Dr. Thomas Zinn for his assistance with SAXS measurements. We thank the HZB for the allocation of neutron/synchrotron radiation beam time and the local contact Daniel Clemens for his assistance with SANS measurements. We thankfully acknowledge HZB for the financial support during the measurement run, the CNRS for financial support of the international associated laboratory "Nano-ions at soft interfaces - NISI" and the "Agence Nationale pour la Recherche" (ANR) for financial support of the CELADYCT project (ANR-12-BS08-0017).

\section{REFERENCES}

(1) Heskins, M.; Guillet, J. E. J. Macromol. Sci., Chem. 1968, 2, $1441-1455$

(2) Halperin, A.; Kröger, M.; Winnik, F. M. Angew. Chem., Int. Ed. 2015, 54, 15342-15367.

(3) Hammouda, B.; Jia, D.; Cheng, H. Open Access J. Sci. Technol. 2015, 3, 1-8

(4) Cho, Y.; Zhang, Y.; Christensen, T.; Sagle, L. B.; Chilkoti, A.; Cremer, P. S. J. Phys. Chem. B 2008, 112, 13765-13771.

(5) Tiktopulo, E. I.; Uversky, V. N.; Lushchik, V. B.; Klenin, S. I.; Bychkova, V. E.; Ptitsyn, O. B. Macromolecules 1995, 28, 7519-7524.

(6) Du, H.; Wickramasinghe, R.; Qian, X. J. Phys. Chem. B 2010, 114, 16594-16604.

(7) Pérez-Fuentes, L.; Drummond, C.; Faraudo, J.; Bastos-González, D. Soft Matter 2015, 11, 5077-5086.

(8) Zajforoushan Moghaddam, S.; Thormann, E. Langmuir 2017, 33, 4806-4815.

(9) Pica, A.; Graziano, G. Phys. Chem. Chem. Phys. 2015, 17, 2775027757. 
(10) Zhang, Y.; Cremer, P. S. Curr. Opin. Chem. Biol. 2006, 10, 658663.

(11) Furyk, S.; Zhang, Y.; Ortiz-Acosta, D.; Cremer, P. S.; Bergbreiter, D. E. J. Polym. Sci., Part A: Polym. Chem. 2006, 44, $1492-1501$.

(12) Zhang, Y.; Furyk, S.; Sagle, L. B.; Cho, Y.; Bergbreiter, D. E.; Cremer, P. S. J. Phys. Chem. C 2007, 111, 8916-8924.

(13) Okur, H. I.; Hladílková, J.; Rembert, K. B.; Cho, Y.; Heyda, J.; Dzubiella, J.; Cremer, P. S.; Jungwirth, P. J. Phys. Chem. B 2017, 121, 1997-2014.

(14) Heyda, J.; Dzubiella, J. J. Phys. Chem. B 2014, 118, 1097910988.

(15) Zhang, Y.; Furyk, S.; Bergbreiter, D. E.; Cremer, P. S. J. Am. Chem. Soc. 2005, 127, 14505-14510.

(16) Chen, X.; Yang, T.; Kataoka, S.; Cremer, P. S. J. Am. Chem. Soc. 2007, 129, 12272-12279.

(17) Dalgicdir, C.; Rodríguez-Ropero, F.; Van Der Vegt, N. F. A. J. Phys. Chem. B 2017, 121, 7741-7748.

(18) Rodríguez-Ropero, F.; Van Der Vegt, N. F. A. Phys. Chem. Chem. Phys. 2015, 17, 8491-8498.

(19) Mukherji, D.; Wagner, M.; Watson, M.; Winzen, S.; de Oliveira, T.; Marques, C.; Kremer, K. Soft Matter 2016, 12, 7995-8003.

(20) Kang, Y.; Joo, H.; Kim, J. S. J. Phys. Chem. B 2016, 120, 1318413192 .

(21) Hofmeister, F. Zur Lehre von Der Wirkung Der Salze, 1888.

(22) Naskar, B.; Diat, O.; Nardello-Rataj, V.; Bauduin, P. J. Phys. Chem. C 2015, 119, 20985-20992.

(23) Buchecker, T.; LeGoff, X.; Naskar, B.; Pfitzner, A.; Diat, O.; Bauduin, P. Chem. - Eur. J. 2017, 23, 8434-8442.

(24) Buchecker, T.; Schmid, P.; Renaudineau, S.; Diat, O.; Proust, A.; Pfitzner, A.; Bauduin, P. Chem. Commun. 2018, 54, 1833-1836.

(25) Kobayashi, D.; Nakahara, H.; Shibata, O.; Unoura, K.; Nabika, H. J. Phys. Chem. C 2017, 121, 12895-12902.

(26) Moussawi, M. A.; Haouas, M.; Floquet, S.; Shepard, W. E.; Abramov, P. A.; Sokolov, M. N.; Fedin, V. P.; Cordier, S.; Ponchel, A.; Monflier, E.; Marrot, J.; Cadot, E. J. Am. Chem. Soc. 2017, 139, 14376-14379.

(27) Moussawi, M. A.; Leclerc-Laronze, N.; Floquet, S.; Abramov, P. A.; Sokolov, M. N.; Cordier, S.; Ponchel, A.; Monflier, E.; Bricout, H.; Landy, D.; Haouas, M.; Marrot, J.; Cadot, E. J. Am. Chem. Soc. 2017, 139, 12793-12803.

(28) Marcus, Y. J. Chem. Soc., Faraday Trans. 1991, 87, 2995-2999.

(29) Assaf, K. I.; Ural, M. S.; Pan, F.; Georgiev, T.; Simova, S.; Rissanen, K.; Gabel, D.; Nau, W. M. Angew. Chem., Int. Ed. 2015, 54, 6852-6856.

(30) Nau, W. M.; Assaf, K. Angew. Chem., Int. Ed. 2018, 57, 1396813981.

(31) Leontidis, E.; Christoforou, M.; Georgiou, C.; Delclos, T. Curr. Opin. Colloid Interface Sci. 2014, 19, 2-8.

(32) Chetcuti, P. A.; Moser, P.; Rihs, G. Organometallics 1991, 10, 2895-2897.

(33) Jallet, V.; Guillemot, G.; Lai, J.; Bauduin, P.; Nardello-Rataj, V.; Proust, A. Chem. Commun. 2014, 50, 6610-2.

(34) Landsmann, S.; Wessig, M.; Schmid, M.; Cölfen, H.; Polarz, S. Angew. Chem., Int. Ed. 2012, 51, 5995-5999.

(35) Zhou, J.; Yin, P.; Chen, X.; Hu, L.; Liu, T. Chem. Commun. 2015, 51, 15982-15985.

(36) Song, Y.-F.; McMillan, N.; Long, D.-L.; Thiel, J.; Ding, Y.; Chen, H.; Gadegaard, N.; Cronin, L. Chem. - Eur. J. 2008, 14, 23492354.

(37) De Viguerie, L.; Mouret, A.; Brau, H. P.; Nardello-Rataj, V.; Proust, A.; Bauduin, P. CrystEngComm 2012, 14, 8446-8453.

(38) Yan, Y.; Wang, H.; Li, B.; Hou, G.; Yin, Z.; Wu, L.; Yam, V. W. W. Angew. Chem. 2010, 122, 9419-9422.

(39) Musumeci, C.; Rosnes, M. H.; Giannazzo, F.; Symes, M. D.; Cronin, L.; Pignataro, B. ACS Nano 2011, 5, 9992-9999.

(40) Li, H.; Sun, H.; Qi, W.; Xu, M.; Wu, L. Angew. Chem., Int. Ed. 2007, 46, 1300-1303.
(41) Kurth, D. G.; Lehmann, P.; Volkmer, D.; Cölfen, H.; Koop, M. J.; Müller, A.; Du Chesne, A. Chem. - Eur. J. 2000, 6, 385-393.

(42) Malinenko, A.; Jonchère, A.; Girard, L.; Parrès-Maynadié, S.; Diat, O.; Bauduin, P. Langmuir 2018, 34, 2026-2038.

(43) Zemb, T.; Lindner, P. Neutrons, X-rays and Light: Scattering Methods Applied to Soft Condensed Matter; Elsevier: Amsterdam, 2002.

(44) Bera, M. K.; Antonio, M. R. ChemistrySelect 2016, 1, 21072112.

(45) Bera, M. K.; Qiao, B.; Seifert, S.; Burton-Pye, B. P.; Olvera De La Cruz, M.; Antonio, M. R. J. Phys. Chem. C 2016, 120, 1317-1327.

(46) Liu, H.; Luo, J.; Shan, W.; Guo, D.; Wang, J.; Hsu, C.; Huang, M.; Zhang, W.; Lotz, B.; Zhang, W.; Liu, T.; Yue, K.; Cheng, S. Z. D. ACS Nano 2016, 10, 6585-6596.

(47) Tang, J.; Ma, C.; Li, X.-Y.; Ren, L.-J.; Wu, H.; Zheng, P.; Wang, W. Macromolecules 2015, 48, 2723-2730.

(48) Bauduin, P.; Prevost, S.; Farràs, P.; Teixidor, F.; Diat, O.; Zemb, T. Angew. Chem., Int. Ed. 2011, 50, 5298-5300. 